\section{ON Ö̈PHORECTOMY IN THE TREATMENT OF CANCER.*}

BY STANLEY BOYD, F.R.C.S., Surgeon to Charing Cross Hospital.

FEw things stand out more clearly when one reviews the progress of surgery during the last fifteen years than the growing determination manifested by operating surgeons to be no longer foiled in their endeavours to cure cancer. Possessed by a firm belief in the local origin of the disease, guided by a good general knowledge of the channels along which it tends to spread, and having thus a clear object in view-namely, the complete removal of the primary focus of disease, of parts directly infiltrated from it, and of all the lymphatic vessels and glands directly connected with the affected parts-everyone worthy the name of "surgeon" must, when operating upon cancer cases, have been conscious of the feeling to which I have alluded, and will doubtless have had now and again the satisfaction of knowing that he had advanced a step, that he had made a wider and cleaner sweep of the disease than usual, and had thus rendered recurrence less likely. Each surgeon must use his own judgment as to how far it is right to go in the interests of each patient. This much seems certain, that though unnecessary mutilation is much to be regretted, it is better, in a mortal malady like cancer, to go too far and remove too much than to stop short and leave foci of disease behind. Each case has its lesson for us-too often a painful oneshowing that we did not remove sufficient skin, that we did not follow up the lymph tract sufficiently far, and so on ; and thus we are being constantly driven to operate more and freely in the first instance.

In face of the statistics published of late years no one can feny that these extensive operations have been followed by long immunity from disease in a considerable number of cases, the frequency and length of the immunity increasing in proportion as the operation practised has been free and carefully and intelligently carried out. I speak of prolonged immunity, for we do not yet know when the liability to recurrence ceases; that cancer germs may lie latent in a lymphatic gland for ten years and then grow is a fact which I learnt not so very long ago. There are many points in the natural history of cancer which require working out, and with regard to these and to the ultimate results of treatment no one is so well able to help as the general practitioner. Whoever now publishes a series of unselected cases traced to the end, indicating shortly the state before operation, the extent of the operation, and the subsequent history, does a piece of really good work, and I hope that some of those here present may be induced to share their experience with others.

But although operation, carried out with modern completeness, is the only treatment which one can recommend at present in early cases of cancer, there are cases enough in which nothing local can be done, or in which local treatment will almost certainly fail to give long immunity. In such, attempts at cure have been made by constant compression, various dietaries, chian turpentine, pyoktanin, arsenic, hydrastis canadensis, celandine, thyroid extract, and anticarcinomatous sérum prepared in different ways. But time will not allow me to do more with regard to these and similar methods than to express my strong opinion that cases of reported "cure" of cancer should no longer be cast aside as incredible, but should receive careful examination and consideration. There has not been much to encourage us to work in this line, it is true; but a conviction that cancer is incurable (except by early operation) may have blinded us to signs pointing the other way, and (while admitting that there is but little to be said in favour of hope) I have lately come to feel that absolute hopelessness is not justified.

On November 27th, 1896, Mr. Pearce Gould showed a case at the Clinical Society of which the history runs as follows: A woman received a blow on the left breast in 1885 ; some tenderness resulted. A small lump was noticed in 1888, and amputation of the mamma was performed by Mr. Collins at

* Read before the East Anglian Branch of the British Medical Association. the Temperance Hospital in 1890 . In 1892 a recurrence in the left axilla was removed, and in 1894 nodules in the scar and one above the right breast were similarly dealt with; but in December, 1894, a further recurrence in the scar, accompanied by some dyspncea, caused $\mathrm{Mr}$. Collins to decline to undertake any further operation.

In January, 1895 , she was admitted to the cancer ward of the Middlesex Hospital, where she was first seen by $\mathbf{M r}$. Gould in March 1896. She was then 44 years and 8 months old, and was suffering from great dyspncea, absolute orthopnœa, frequent cough, and free expectoration, which had been tinged with blood on two occasions. The right chest was dull up to the spine of the scapula, and presented all the signs indicating fluid in the pleura. No evidence of growths in other viscera, particularly the liver, was discovered. But there was much pain complained of in the left thigh, and a considerable swelling of the femur below the great trochanter was found, accompanied by such bowing outwards of the femur as to give rise to a good inch of shortening. About this time she had a painful swelling, as large as a hen's egg, first in the right and later in the left groin; both ultimately subsided under fomentations. Round the scar on the left chest were numerous hard nodules, and both in the axilla and above the clavicle a good many glands were considerably enlarged; this was the case also, though to a lessextent, in the right axilla and above the right clavicle. Three months later (June I 5 th) this patient, whom Mr. Gould in March naturally regarded as doomed to speedy death, was. much better, though no treatment which could be regarded as curative had been adopted. She could now lie comfortably in bed, and there was no dyspnoea; the nodules about the scar had gone, with the exception of one tiny one which. soon disappeared; the swelling on the femur had diminished. On November 27th, 1896, this patient was shown at the Clinical Society, apparently in ordinary health; she walked lame because her femur was so markedly bent and shortened, but it bore her weight well and painlessly; all superficial evidence of cancer had gone; resonance at the base of the right pleura was slightly impaired; enlargement of the femur was gone, leaving only the curving above noted.

The clinical course of this case renders its nature sufficiently clear and certain, but the growth was examined. microscopically at the Temperance Hospital by two competent observers, and noted to be "ordinary scirrhus." This patient ceased menstruating in January, 1896, when she was very ill; no menstrual flow accompanied the regaining of her health and strength.

With Mr. Gould's consent, I visited this patient at Woodford, in Essex, on August, I 7th, 1897. She stated that in April she had apparently fainted in her room, and had fallen so as to injure her bowed left femur. She was taken to the Middlesex Hospital, but the house-surgeon found no reason for taking her in. She had left the hospital early in November, 1896 , and from that time up to this fall had been able to walk out far enough to do her "bit of shopping" without the aid of any support. Since the fall she had not been able to bear weight on the left foot because it caused pain in the left thigh. After this accident she appears to have run down considerably, owing, as her sister thinks, toconfinement in a poor room in a crowded part of London. Finally, she got bronchitis, and her sister then (in June) took her to live at Woodford, and looked after her well. She now lost her bronchitis in a fortnight, appetite improved, she put on flesh, pain in the thigh when used as a support lessened, and she was hoping to regain use of the limb when, on Thursday last (August 12 th), whilst sitting sewing on a. low chair she again fainted, and, falling on to the floor, hurt her thigh once more, and has been in bed since. Previous to this she had been able to get about on crutches well enough to. dust and tidy her room. On one or two occasions she had. managed to get down a short flight of stairs into the garden, but had "come over faint" while sitting there.

As to the "present state," she is very bright and cheerful, not suffering any pain, sitting up in bed and performing other required movements briskly and without obvious effort. She is anæmic and thin. I could find no trace of cancer in the superficial parts of her chest wall, in the axillæ or supraclavicular regions, though the left supraclavicular fossa is a little fuller than the right. The abdominal viscers appeas 
normal. The left inguinal glands are plainer than the right, but can hardly be described as enlarged. The left lower limb is not more than $1 \frac{1}{2}$ inch shorter than the right, though the patient thinks that the bowing and thickening of the femur have increased. The femur certainly is thickened and obscured a little below the trochanter. There is no valvular heart disease, but the pulse is wretchedly feeble.

At the same meeting of the Clinical Society Mr. Bowlby was able to mention another very unusual case which he had seen under the care of Mr. Willett, and Mr. Willett has been good enough to supply me with further details of this case and to allow me to make use of it :

A lady of $\mathbf{4 2}$ had a scirrhous breast and axillary glands removed by $\mathrm{Mr}$. Willett in April, 1893. In April and October, 1895, large portions of the pectoralis major were removed for recurrent growths in it. In November this patient went to live at Eastbourne under the care of Dr. Harding, from whom Mr. Willett has obtained for me a series of careful notes. In December, 1895, widespread nodules appeared in and around the scar, and a supraclavicular gland was enlarged; no further operation was deemed advisable. On February i ith obstinate and frequent vomiting began, the vomit consisting of food streaked with blood. On the r 3 th, acute pain started in the left hip and the patient became bedridden; the limb lay helpless, wasted quickly, and even jarring of the bed excited the pain. On the 22nd slight jaundice was detected, and there was acute pain with tenderness over the liver, which was considerably and irregularly enlarged. During the first week in March fresh nodules appeared in the right axilla and above the left clavicle, while the right supraclavicular glands increased in size. So far advance was steady and rapid, but in this month (March) the last regular period occurred-a "show," lasting a few hours only, appearing in May.

Improvement now began, and on the whole continued for some months. In August the patient was at her best; she was out daily, was in good spirits. had lost all cachexia, and had certainly gained flesh. In September pain in the hip had become so slight that she was allowed to walk, and did so daily for a fortnight, when she caught cold and was again confined to bed. After this slow failure began. In November, 1896, great irritability with attacks of depression began and increased. In February, I 897 , slight delusions appeared, and in March "pins and needles" in the left hand and loss of power in the left arm were complained of. The patient was now failing very markedly, and died in April, 1897, under circumstances to be presently detailed.

The improvement which began in March, 1806 , was not confined to general health. First, the vomiting subsided; it ceased in April, and, except for a fortnight in June, did not recur. In April all superficial growths (skin, fat, and glands) began to soften and atrophy, a process which continued during the period of general improvement; but it is not stated that any nodule actually disappeared. In May an ulcer, the size of a threepenny bit, formed in the scar, but bealed in July shortly before a fresh crop of secondary nodules appeared upon the back and back of the neck. These nodules apparently soon began to share in the atrophy of such growths which was going on. In March, 1897, several similar nodules appeared over some of the dorsal spines, and another small ulcer appeared in the scar, but healed within a week, although at this time the patient was in a very depressed condition. The most interesting of the secondary growths, however, was one connected with the upper end of the right humerus, in which severe pain had been suffered since April, 1896. On June 28th a very hard swelling was found here; it increased for a month, was accompanied by œdema of the hand and forearm, and then began to subside. On November 13th a very hard swelling was again found at the same spot; it increased to the size of a goose's egg, only again to disappear in January, 1897, together with the accompanying cedema of hand and forearm. On April 18th, 1897, the patient being now very feeble, Dr. Harding found the right humerus broken high up. The fracture was not preceded by any fresh swelling, and the patient was quite unaware that anything of the kind had happened. She now got rapidly worse. The temperature rose to $105^{\circ}$ almost daily; she became delirious, wasted rapidly, and died on April 26th. No lung trouble was detected.
I think I am justified in saying that we have here two indubitable cases of cancer, in the first of which apparently complete and prolonged disappearance of widespread lesions occurred; whilst in the other a remarkable series of attempts in the same direction was made-for example, wasting of superficial nodules, healing of cancerous ulcers, disappearance of two growths around humerus, and marked improvement in general condition. In neither case was any treatment which can be regarded as curative employed, and in both cases the improvement dated from the menopause-a fact which I note but do not desire to lay too much stress upon, as the concurrence may well have been fortuitous.

The simple argument which I tase upon these cases is that if by clinical and pathological observation or by therapeutic experiment we can discover the conditions which lead to such atrophy of cancer masses, we may further succeed in artificially producing these conditions and thus inducing atrophy. Though not at present a believer in the parasitic origin of cancer-that is, in the causation of the disease by a specific micro-organism-1 regard the cancer cells lying in blood vessels or lymphatics as invading parasites just as similarly situated bacteria or psorosperms would be. Exactly the same sort of struggle must be going on between the epithelial cells and the tissues in which they have come to lie as occurs between invading micro-organisms and the tissues. Following out the analogy, weak resistance on the part of the tissues, possibly excessive virulence (if I may theorise so far) on the part of the epithelial cells, will result in "acute cancer," rapid spread occurring locally or generally, or both locally and generally. The contrary conditions under which the tissues do not afford a suitable nidus for the growth of epithelium result in an implantation cyst or in a more or less atrophic cancer, the course possibly extending over ten, fifteen, or twenty years. We are all familiar with these acute and chronic varieties in, say, tubercle; and in this malady complete recovery is also well known. I suggest that the two cases which I have quoted should be regarded as instances in which a very high degree of resistance to the parasitic epithelial cells was developed, and that these cells consequently died, degenerated, and were absorbed, as all cells do when unable to obtain sufficient or suitable food.

If there be any truth in this view, the search for a cancer antitoxin may not be vain; but I do not propose to discuss the very doubtful results so far obtained in this line of research. I wish rather to draw your attention to a method of treatment by which atrophy cf cancer masses has, in some instances, been induced.

On May 20th, 1896, Dr. Beatson, of the Glasgow Cancer Hospital, read a paper before the Edinburgh Medico-Chirurgical Society on the reasoning which led him to think that removal of the ovaries might arrest breast cancer. Dr. Beatson showed, in illustration of his views, two cases in which he he had carried out the treatment.

The first patient was a married woman, aged 33 , who had had two children, aged 3 and $1 \frac{1}{4}$ years respectively. In her first lactation she noticed a painless lump in the outer side of her left breast. Only in her second lactation, twenty months later, did she notice increase in this lump, and she sought no advice until she had suckled this second child for ten months. She was then in good health, but had a tumour $5 \times 3 \frac{1}{2}$ ins., with nodules in the superjacent skin, one of which was ulcerating. An extensive operation was performed at one of the Glasgow infirmaries, but recurrence was evident almost before the wound was healed, and further operation was deemed useless.

Dr. Beatson saw this patient on May IIth, 1895. Her health was beginning to break down. About the middle of the scar was a prominent recurrent mass, $3 \frac{1}{1} \times 2 \frac{1}{2}$ ins., adherent to the chest wall; and smaller nodules ran along the scar back into the axilla. No large glands could be felt, and no viscera seemed to be affected. A bit of the growth was excised and shown to be cancer. For a month thyroid extract was given fully without result.

On June 15 th Dr. Beatson performed double oöphorectomy, and on July i2th thyroid extract was again begun, Dr. Beatson regarding it as a powerful lymphatic stimulant.

On July igth (five weeks after the oöphorectomy) the large mass was smaller and less vascular, and similar changes were 
evident in the minor nodules. The tissues around were softer and more pliable.

On August ist (seven weeks) each diameter of the large mass had shortened 0.75 in. $\left(2 \frac{3}{4} \times 1 \frac{1}{4}\right.$ ins.), and its thickness was hardly appreciable; its colour was yellow-white, its vascularity slight. The smaller axillary nodules, though shrinking, did not keep pace with the main mass. The general health was now satisfactory, and the patient went for a change of air.

On October i 2 th (four months) the main mass was reduced to a yellow lamina, not raised above the skin. The axillary nodules were smaller, thinner, and yellowish. No new nodules had appeared, and the patient appeared to be and felt very well. She was now taking 20 grains of thyroid daily.

February, 1896 (eight months). All trace of disease had gone.

On May 2oth, 1896, the patient was shown at the Edinburgh Medico-Chirurgical Snciety, and was examined by Bell, Chiene, Stiles, and most of the well-known surgeons of the northern capital; all expressed themselves as satisfied that the case had been one of true cancer, and that no trace of the disease was at that time discoverable.

In June, 1897 , Dr. Beatson writes that this patient remains to all appearance well-two years after the oöphorectomy.

Dr. Beatson's second case differed from the first in many respects. She was a chronic alcoholic, aged 30 , married : no children, menstruating every three weeks. She was thin pale, worn, but still fairly strong. A large tumour of five and a-half year's' growth occupied all the right breast except the extreme lower edge. The skin was thick and red over a large area. The mass was not fixed to the chest. Increase had been rapid since a blow nine months ago. The axillary glands were swollen and rather fixed, the pectoral fold thickened, and shotty nodules were felt over the first space and over the clavicle. There were many large glands in the right, and one in the left, posterior triangle. No visual infection was detected. During a month no treatment was adopted, and steady spread occurred in all directions; large glands now reached up to the right angle of the jaw in both anterior and posterior triangles, and many more cutaneous and subcutaneous nodules had appeared. Pain and stiffness in the neck rendered opiam a necessity to obtain sleep.

This patient now consented to a double oöphorectomv, which was done on October 3 rd, 1895, adhesions rendering it difficult. Nine days later (October I 2 th) vascularity over the tumour was less, and pain had all but gone. She was "in a different world" slept without opium, and moved her neck more freely. Thyroid extract, 10 grains per diem, was now begun. At the end of two months (December 3 rd) the tumour was sufficiently shrunken to allow infiltrated skin to be raised from it: A nodule now excised showed marked fatty degeneration and increase of fibrous tissue; the wound healed soundly. On January roth, 1896 (fourteen weeks after oöphorectomy) she went to the coast, neglected to take the thyroid extract, and probably drank more than was good for her. On February 25 th (five months) she was looking well, but increase had again set in, and the skin was reddened over some cervical glands. In bed, on 15 grains of thyroid per diem, some improvement occurred, but it soon ceased, and the patient died with secondary growths in the liver.

This was a case which, in its earlier, slowly growing stage, ought, one would think, to have been amenable to this treat ment. But when the oöphorectomy was done the disease was very widely distributed, her early resistance was broken down, enormous numbers of the epithelial cells were present, were growing actively, and pouring their products into her system. Even under these unfavourable circumstances a distinct effect was produced, and continued for some five months.

Dr. Beatson spoke at meetings of the British Gynæcological Society in March and April of this year. Without giving details he stated that in three other cases of otherwise inoperable cancer of the breast treated as above described, he had obtained only a trifling and very short improvement. consisting chiefly in diminution of vascularity and relief of pain. He seemed despondent as to the future of the treatment.

So far as Dr. Beatson is concerned I have now brought you up to date, and I will next turn to my own small experience. I have operated on five cases; but, as my first case dates only from December, 1886 , I lay myself open to the criticism that I am reporting them too early. Nevertheless, I hope you will find them interesting, so far as they have gone.

CaSE I.-My first case was sent to me by Mrs. Garrett Anderson in June, r896, for an opinion as to whether anything further could be done. Mrs. Anderson had operated upon this lady for cancer of the left breast in September, 1892 , a few days after the patient first noticed that anything was
wrong. The growth seemed to be simple, and was alone removed; but in June. I $_{933}$, continued growth rendered removal of the breast necessary. The patient was then lost sight of until May, 1896 , when she reappeared with recurrences of from eighteen month' to two years' standing. The with recurrences of from eighteen months to two years' standing. The
patient was now aged 44, and was menstruating regularly. Although she had suffered from cancer for certainly over three and a half years. her fine physique had not broken down in any way, and I could find no evidence of visceral disease. Locally she presented a large nodule in the pectoralis major, above the scar, movable over the ribs. The axillary glands were almost certainly affected, though none could be felt. There were a few subcutaneous nodules round about the scar, and one small mass adherent to the chest wall in the neighbourhood of the fourth and fifth cartilages. The doublful point was whether anything radical could be done with this latter growth. In luenced by the splendid condition of the patient I offered to make an attempt to remove it widely, with the understanding that if this could be satisfactorily carried out the operation should be completed by the removal of the great pectoral muscle and thoroughly clearing-out of the axilla. On July gth, 1896 . I cut freely round this mass, and removed it, together with the whole of the fourth and fifth cartilages. I then found a large anterior mediastinal gland, which I shelled out easily ; but, f seling that there must be others higher up. I closed the wound. But for a little accumulation of bloody serum, healing took place without difficulty, leaving a deep hollow, at the bottom of which the heart could be felt with unpleasant distinctness. Some months later this lady heard that Dr. Beatson had discovered "a cure for cancer." He had at that time published his first two cases, and the second was beginning her downward course. I explained exactly how matters stood, how absome additional evidence had come to light, and had been commu-
nicated to them, the patient and her husband decided to have oöphornicated to them, the

At this date, patient being now 45, and menstruating regularly, there was marked swelling above the scar, due chiefly to a mass, the size of a large walnut, in the pectoralis major; not fixed. There was fulness above ous nodules were distributed, as shown in the diagram (Fig. I). A dense

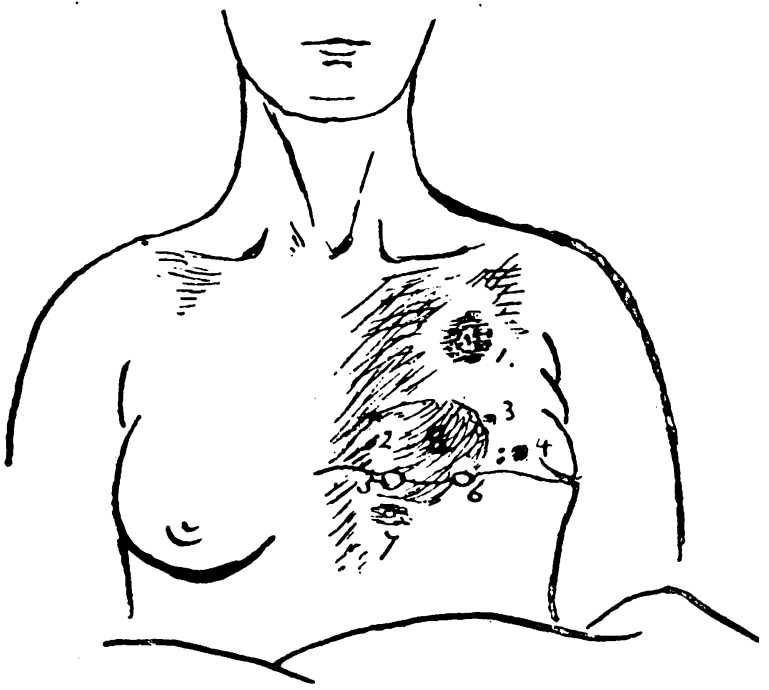

Case I, Fig r.-December зoth, 1896. (r) Mass in pectoral ; much swelling around. (2) Prominent inner end of depression (8), through floor of which heart beats could not be felt. (3 and 4) Subcutaneous nodules. (5) Thin red plaque in scar. (6) Nod

mass of cancer, through which no cardiac impulse could be felt, occupied the site of the depression due to removal of the fourth and fifth cartilages No visceral lesion was found. There was constant pain in the pectoral region, increasing of late, "like a claw drawing it together." Double oöphorectomy was performed on December

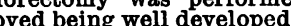

The immediate result of the operation was relief of pain. At the end of a week, vascularity of the nodules was less, the general fulness in the pectoral region was much less, and nodule No. was decidedly less prominent. Three weeks (Fig. 2) after the operation No. 5 was all but gone, and the heart impulse could be plainly felt through the infiltrated depressed area After four weeks I noted: The certain improvements are-loss of all pain, reduction of general swelling and hardness, diminution of vascularity of all lesions, disappearance of the small red scar-like patch (No of No. 7 , which used to raise the skin; disappearance of induration from 
the floor of the depression. The pectoral mass has shrunk more slowly; and a good deal of cancer probably remains, forming an abrupt promi-

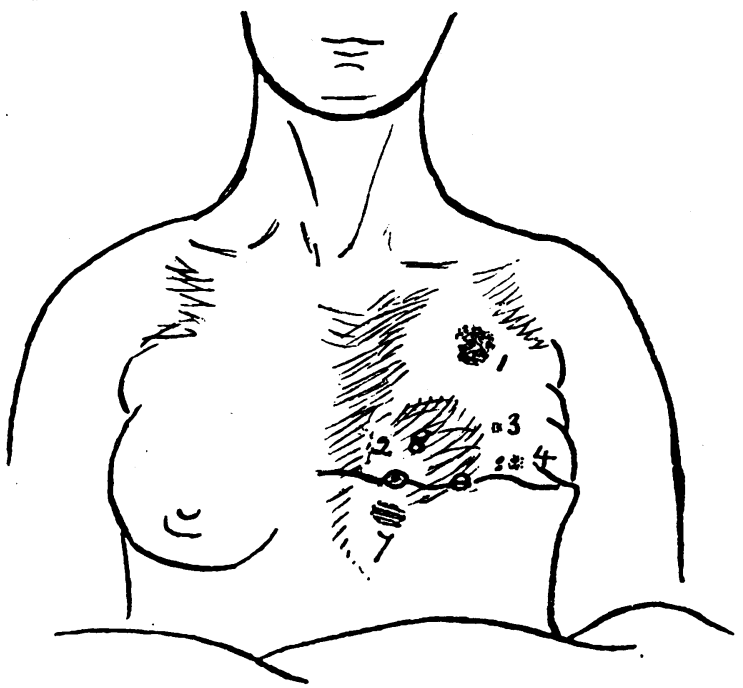

Case I, Fig 2.-January roth, r897. General swelling less. (x) Is consequently more distinct and movable, smaller? (2) More defined, exact nature? (3 and 4) Smaller. (5) Gone. (6) All but gone. (7) No longer obvious, but some thickening still about rib cartilage. (8) Floor soft, heart impulse clear to eye and touch ; edges
of ribs and cartilages around are obscured by new growth. nence at the inner end of the depression. Nodules Nos. 3 and 4 have steadily, though slowly, diminished. Nine weeks (Fig. 3) after the

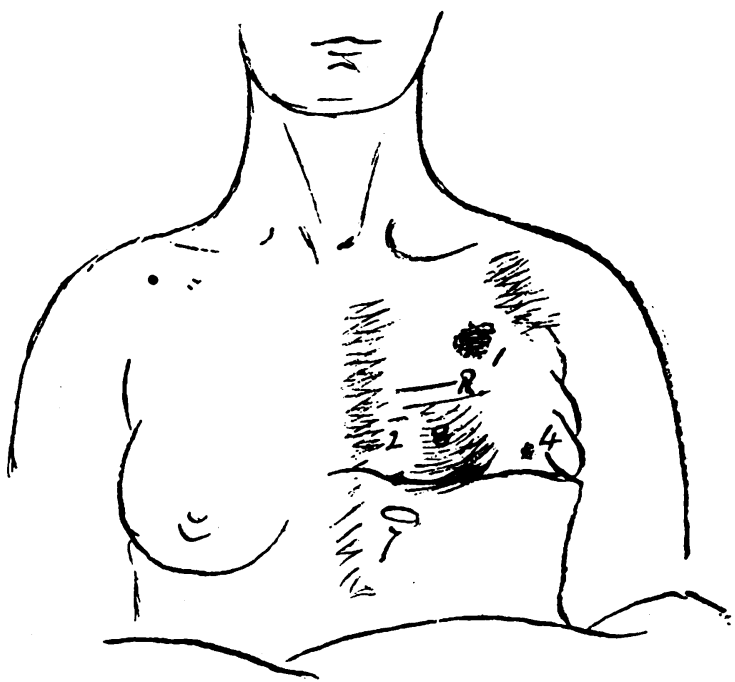

Case 1, Fig. 3.-February 22nd, 1897. General swelling gone. (r) Rather smaller. (2) Nature still doubtful. (4) The largest of the three nodules remains, though smaller. (7) Very doubtful if any thickening remains. (8) Infiltration of floor gone, heart beats quite plain. The third rib $(R)$ is now plainly felt above depression.

operation the general health was excellent. The pectoral nodule was smaller, but still considerable; it was moving much more slowly than most of the skin and subcutaneous nodules. All infiltration seemed to have gone from the floor of the depression, but I could not be certain as to the nature of the prominence at its inner end-that is, whether it consisted of cancer or of the tissues on the side of the stornum hardened by scar tissue, and possibly by bone. The third rib cartilage was quite clear above the depresslon. 4 small single nodul could almost if not entirely gone. At the end of May, 1897, this patient was in excellent hoalth; she had been for some weeks confined to the house, and even to bed, by bronchitis (from which she is not now entirely free), and has lately been at the seaside. There was no evidence of secondary growth in the lungs. Littlo or ho chang had occurred in the pectora growth and in the larger of the throe nodules marked No. 4. If anything, theso nodules wero there was some cancer tissue in the abrupt prominence at the inner end

August Ith. In May' I thought this patient had reached a point 11

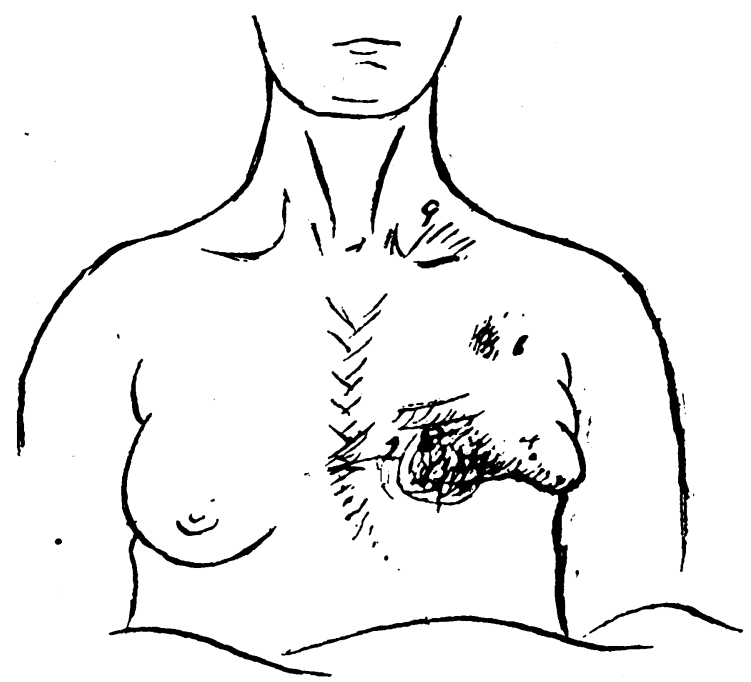

Case r, Fig. 4.-(x) Very much smaller. (2) Sharp and natura instead $^{-}$ of blurred. (4) Present? (8) Pulse clear to eye and touch. Base smooth and firm, as if dense fibrous tissue. (9) Fulness?

beyond which she would not improve. At the end of June she went to Yorkshire, and remained there for, five weeks (till July zoth). She now looks the picture of health, has gained strength and energy markedly and has gained flesh, weighing now close on 12 stone. Her husband says she is " very well." The pectoral mass (No. I) is much smaller-perhaps one-third of its size in May. The nodule No. 4 has all but disappeared; think $I$ can still feel something about where it used to be. The floor of the depression (No. 8) is firm, smooth, and gives the impression of tense fibrous tissue drawing the cut ends of the ribs inwards. The heart impulse is both visible and palpable through it. The prominence at th inner end of the depression is smaller, and to the touch very different, a bony sharp edge being now clear where formerly was a mass with blurred
outlines. I have strongly advised this lady to go back to Yorkshire, and to remain there for some time longer.

CASE Ir.-My next patient, 37 years old, and unmarried, was sent to me CASE Ir.-My next patient, 37 years old, and unmarried, was sent to me by Dr. Horace Sanders, of Camden Road, in March, 1896. She had included a mass 3 by 2 inches in the right breast, closely adherent to the pectoral, and, as 1 found at and after the operation, numerous secondary nodules in the breast itself, in the great pectoral, in the fascia beneath this muscle, on the subclavian sheat $h$, and in the axillary glands. I did a very free operation, and saw no more of the patient till February, 1897, a very free operation, and saw no more of the patient till February, 1897, brought her to me with (Fig. I) multiple nodules in the skin and sub

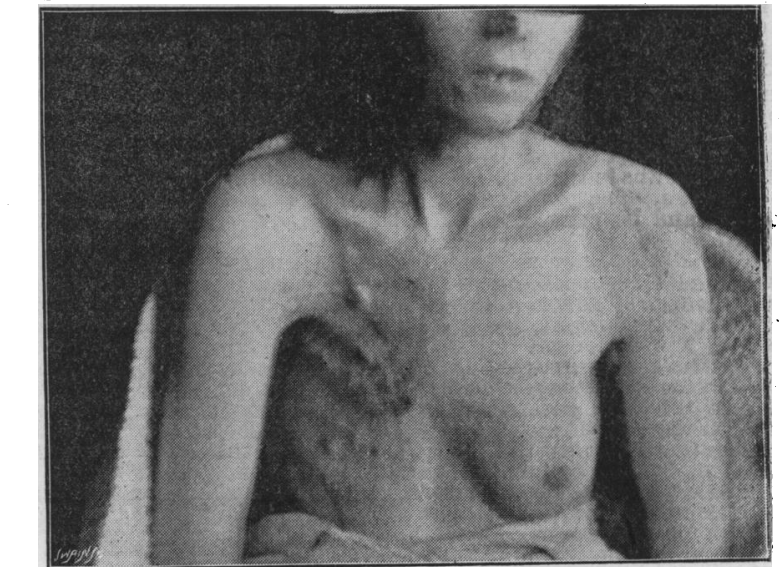

Case 1I, Fig. x.-From a photograph by Dr. Horace Sanders, taken just before the oobphorectomy. These are the chief points shown. Thinness of patient; prominent gland above right clavicle; triradiate scar on right chest, with large nodule at meeting point of branches; a bridle-like prominence running from this up to clavicle with a nodule at its centre; general inflitration of the skin and subcutaneous tissue along and behind the lower limit of the scar, often closely adherent to the chest wall; a lower group of three nodules, of which the posterior is the larger; a nodule in the upper and outer part of left breast. There was a good deal besides which a photograph could not show.

cutaneous tissue in and about the scar, reaching back to mid-axilla, many being adherent to the chest wall. There was one considerable mass in the outer half of the clavicular portion of the pectoralis major (I had 
removed the sterno-costal part), which was probably adherent to the chest wall. In the axilla were one or two gland-like nodules, and above the
right clavicle a gland was obvious to sight. In the upper and outer part of the left breast was a prominent nodule the size of a marble, and a small of the left breast was a prominent nodule the size of a marble, and a small gland could be felt above it in the left axilla. No visceral lesion was made
out. There had recently been much pain in the left thigh, quite crippling out. There had recently been much pain in the left thigh, quite crippling when I saw her, and nothing could be felt in the thigh to account for it. The patient. was very thin and

On February 2r8t, 1897, double oöphorectomy was done, the ovaries being rather small. A week later the nodules were distinctly less vascular, and the hindermost of the three lowest shown in the photograph was now the smallest. This will give some idea of how rapid the atrophy was now the smallest. This will give some idea of how rapid the atrophy equally and simultaneously. At the end of a month (Fig. 2) flesh and

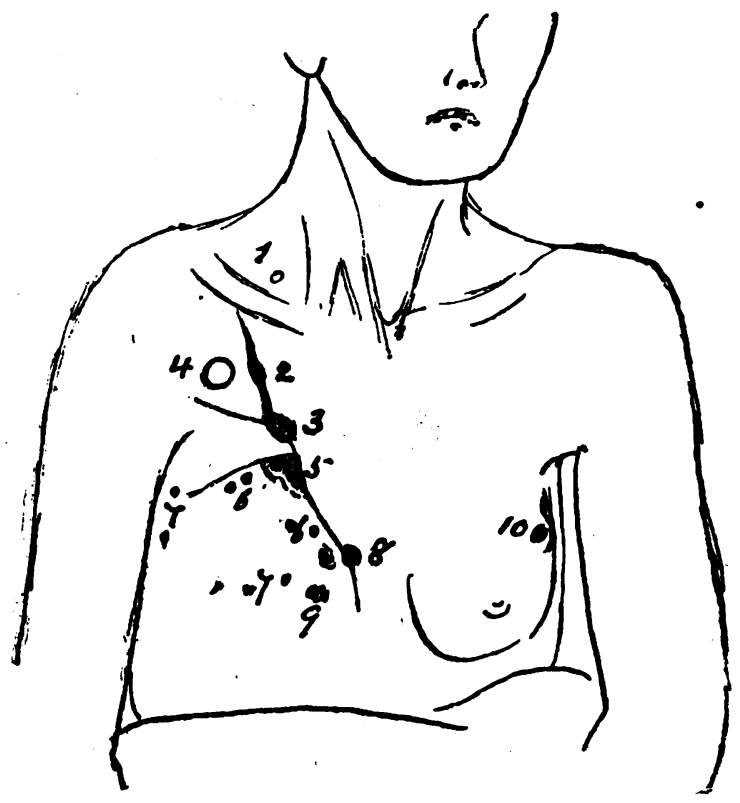

Case II, Fig. 2-March 22nd, r897. First fairly accurate chart taken. (1) Gland size of pea; no longer obvious. (2) Red patch, slight thickening of skin ; bridle almost gone. (3) Reduced to marked thickening of skin, mobile on chest. (4) Nodule in pectoral, probably adherent to chest wail. (5) Vascular ridge of growth surrounding apparently healthy scar. (6) Vascular skn plaques. adherent to fourth cartilage. (9) Thickening or fifth

colour had decidedly been gained. Pain in thethigh had recurred before the operation, but had since disappeared, perhaps from rest and warmth in bed. All superficial lesions were shrinking rapidly; prominent nodules had been reduced to mere plaques, and the attachment of skin lesions to the chest wall was loosening. The gland above the right clavicle could no longer be seen. The prominent ridge shown below the clavicle had flattened out, and its central nodule was reduced to a slight thickening of skin only

On April joth, r897 (ten weeks), this patient came to my house, and she looked so well that 1 thought she had been to the country. Her weight had risen from $6 \mathrm{st}$. ro lbs. (fourteen days before operation) to $7 \mathrm{st}$. $5 \mathrm{lbs}$. (nine weeks after operation) - a gain of 9 lbs. During the last three or four weeks she had been out daily, and could now take a respectable walk and "hold herself up"-as her sister remarked. Locally (Fig. 3) the improvement was very striking; there was slight vascularity and very slight thickening at the site of the nodule in the ridge below the clavicle ; similar changes had occurred at the centre of the triradiate scar, but rather more thickening remained here, the patch being quite movable; the innermost of the three lowest nodules could be felt as a hard point adherenc to the fffth costal cartilage; the skin over it and at two points in the scar whence growths had vanished became vascular after manipulatio $h$; the nodule in the left breast was much smaller and the gland above it had disappeared.

On May 24th (thirteen weeks after operation) I heard that the patient had improved greatly at Hastings, that she walked two miles daily without fatigue, and had gained 2 lbs. more-rI in all since the oöphorectomy

On August 6th (twenty-four weeks after operation) I saw this patient There was nothing noteworthy in her appearance; she seemed bright and fairly brisk in her movements. Strength remains about the same as in May; she has not resumed her former light household duties. The scar (Fig. 4) looks quite normal, and the change in the appearance of th whole chest wall since the operation is most striking. At first "sight all patches seemed to have disappeared; then I noticed faint red patches at spots shown in. Fig. . 4, and found that the skin at these spots was very slightly thickened and that the redness increased with handling. Th two upper patches of the.lowest groups did not certainly correspond to
the lesions marked 7. I could feel no glands above or below the right clavicle; no nodule in the right pectoral, but there seemed to be some

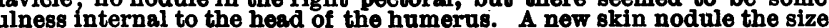
of a split pea had appeared at The nodule in the left breast was thrice as large as in Aprll and involved the skin; two or three small glands had appeared in the left axilla; no visceral growths detected.

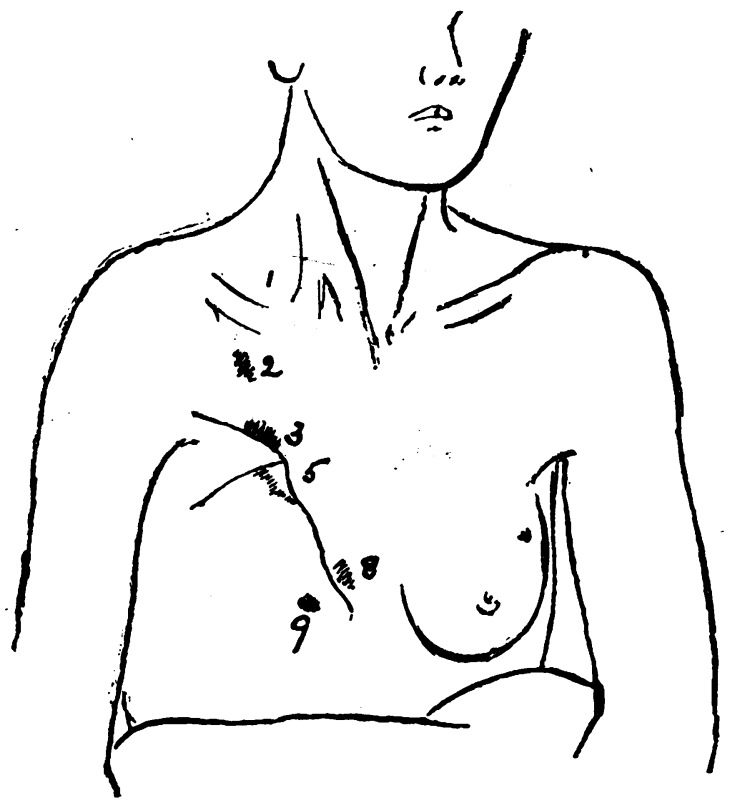

Case Ir, Fig. 3.-April 3oth, 1897. (1) Still felt obscurely. (2) Vascularity and very slight thickening of skin; bridle gone. (3) Vascularity with more thickening; quite movable. $(6,7)$ Gone. (5 and 8) Skin became vascular after manipulation. (9) Ditto; gland in either axilla. (4) Gone, but pectoral seems thick.

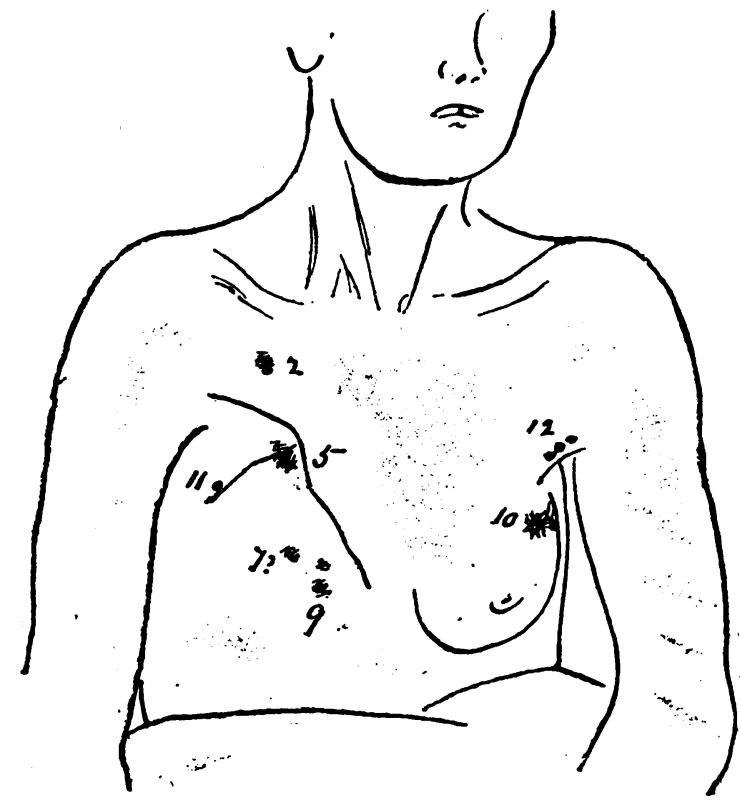

U. Case II, Fig. 4.-August 6th, r89. At first sight the scar and chest (2), (5), ( 7 ?), and (9), increased by handling; skin here very slightly thickened. (II) A new skin nodule as large as a pea. (ro) Perhap thrice as large, dimpling skin. (12) Two or three axillary glands

Cast III.-Mrs. R. S., aged 9, menstruated regularly till October, 1896 not at all since (six months). Her left breast had been removed by Mr. Clement Lucas in August, $189 x$. In October, 1803,8 swelling appeared on her sternum. In December, 1896 , she noticed that her right shoulder was painful and swollen She was transferred to my care by my colleague, 


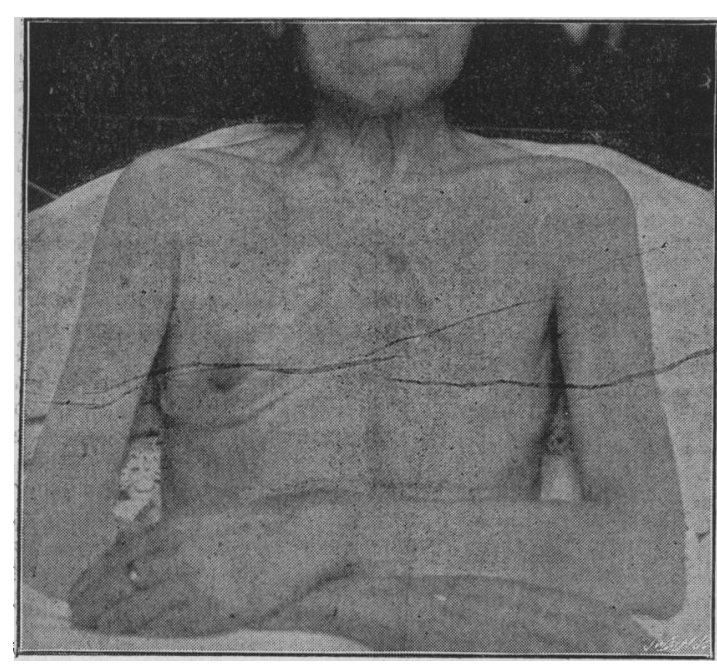

Case III, Fig. 1.-Mrs. R. S., aged 49, oöphorectomy, March 20th, 1897. feeble, and bedridden, suffering from pains in many parts, but particuhumerus was sufficient to show in a photograph. At and below the sternal articulation lay a hard swelling the size of half a large orang (3 by $2 \frac{1}{4}$ inches); on its summit was an ulcer as large as a sixpence. The breast scar and its neighbourhood were sound. The liver projected some three finger-breadths below the ribs. On March zoth I performed double oöphorectomy. The only changes noted while this patient remained in hospital were alleviation of pain and diminution in size of the ulcer on the sternal swelling. Nine weeks after the operation Dr. Jacobs, of wrote me that the patient was steadily getting weaker and thinner; that the pain in the right shoulder had been worse again during the last fortnight; that nausea and vomiting were occasional symptoms, and that the liver projected 3 inches below the ribs; and, later, Dr. Jacobs wrote me that Mrs. S. had died about fourteen weeks from the operation. She had suffered greatly from pain in the right shoulder, the liver continued enlarging, but there was no clear change in the sternal swelling.

CASE IV.-Mrs. J., a widow, aged 64, from whom in April, 8 . 36 , I had removed a large cancerous right breast. In February, 1897, a nodule appeared at the inner end of the second intercostal space encroachin upon and adherent to the sternum. She did not seem to have lost flesh or health. On March 27 th double oöphorectomy was done. The ovaries were so excessively atrophied that it would be difficult to conceive that they discharged any function or exercised any intluence at all upon the rest of the tissues. Eight weeks later the growth had somewhat increased, and the patient was thinner and paler.

CASE V.-My last case was that of a married woman, aged about 45 , menstruating regularly. She had a large tumour of the left breast, involving the skin over a large area, with marked affection of the axillary glands. The general health was very good, and no visceral disease could be detected. I felt that, however thoroughly I might operate in this case recurrence at an early date was only too probable. Dr. Beatson's second case warned me that oöphorectomy alone would very likely prove in sufficient, in the presence of such extensive infection of the tissues, to turn the scales in favour of the patient. Consequently, I first removed a couple of small ovaries, and went on immediately to a wide operation upon the breast and axilla. This was on May igth.

On August 4 th, Dr. Badcock, of New Brompton, wrote me that all was going on satisfactorily with this patient.

I mention the case merely to show that oöphorectomy may probably be usefully combined with the ordinary operation when we have to deal with bad cases.

In Case No. 1, when in May I found the mass in the pectoral at a standstill or even enlarging, I greatly regretted not having removed it at the first operation in June, I896. Had I then done an operation on the recurrences, as complete as possible, the patient might now have been quite free from the disease. The removal of nodules which do not seem inclined to go after an oöphorectomy may help towards a favourable conclusion; so, too, may the removal of the ovaries in somewhat advanced but still operable cases of breast cancer.

The time has not yet come for drawing conclusions as to the value of Dr. Beatson's suggestion in the treatment of cancer, yet I will, with your permission, lay a few of my thoughts upon the subject before you. It seems to me to be in the highest degree improbable that the relationship between the oöphorectomy and the atrophy of the cancer masses which I have described to you is other than causal. How removal of the ovaries can produce such an effect I do not know, but my working hypothesis is that the internal secretion of the ovaries in some cases favours the growth of the cancer, acting either upon the epithelial cells or upon the surrounding tissues; consequently, in these cases, removal of the ovaries will leave the tissues better able to cope with the parasitic cells.

We cannot for a moment suppose the mere cessation of the menstrual flow to be causally connected with the atrophy ; both, most probably, result from the same cause, namely, removal of the internal secretion of the ovary. Why, then, it will be asked, did I remove the ovaries in two women who had passed the menopause? I did so because it seemed to me that cessation of the menses did not by any means prove that the ovaries had become of no more importance, for good or evil, in the body than bits of connective tissue. The internal secretion of the ovary is, doubtless, extremely complex; it was conceivable that after that factor upon which the menstrual flow depended had been altered or eliminated the ovarian cells still secreted the substance which influenced the growth of cancer cells. Consequently, the fact that the menopause had been passed did not appear to me to forbid the trial-the patient understanding that it was a trial-of so slight an operation as oöphorectomy. The results have not been encouraging. The cases selected were not, perhaps, the most favuurable; No. 3 , it is true, had ceased menstruating only six months, but she was very far gone at the time of operation; No. 4 was an old woman, and had hardly any ovaries left ; they were extremely wasted. Nevertheless they support, so far as two cases can do so, the view that when the internal secretion of the ovary ceases to induce menstruation it ceases also to have any influence upon cancer.

But the question of main importance is, whether the atrophy in those cases in which it is induced by oöphorectomy will be permanent? Will it be a "cure"? Obviously, nothing but time can answer the question. At present, so far as I know, only Dr. Beatson's first case has reached the stage of apparently complete disappearance of all lesions. Of my own cases, Nos. I and 2, the latter, notwithstanding the astonishing progress made up to a certain point, seems now (six months after operation) to have again begun a downward course. She has gone to Southend, and I can only hope that the change of air may so improve her general health that, like case No. I (p. 892), she may still make a successful stand against the disease. I should not have ventured even to express such a hope, had I not just seen the effect of change of air (apparently) upon No. 1

Another point of great importance is the frequency with which atrophy can be induced by oöphorectomy. In Dr. Beatson's three last reported cases the effect appears to have been very trifling. I have not full notes of these, but no doubt they were all operated on before the menopause. Does this mean, as I have supposed, that in these cases the interna secretion of the ovary had no share in the production of the cancer? That it influences the cancer process only when it has undergone a pathological variation? In my own cases (I and II) the local response to the oöphorectomy was very prompt. Pain ceased at once; diminution in vascularity soon followed, and in a week some evidence of atrophy was noted. But you will, doubtless, have been struck by the fact that all the cancer lesions did not waste uniformly; even those situate in the same tissue did not do so. Nodules in the skin and subcutaneous tissue seem to be most quickly affected, then enlarged glands; muscle growths come far behind these. Dr. Beatson is strongly of opinion that visceral growths are not arrested by oöphorectomy, and attributes his later failures to the wide extent of the disease. No effect was produced upon the liver in No. IV, but this was after the menopause. Yet, with Gould's and Willett's cases before me, I cannot yet abandon hope for even these cases, although I feel that large involvement of a viscus probably must render recovery proportionately difficult. Acute progress will probably act similarly, but I have no clear evidence.

An early thought to occur to anyone must be that cancers other than cancer of the breast will be influenced similarly by oöphorectomy, for, in spite of clinical and histological differences, we have regarded cancer as essentially the same wherever it occurs. I have not myself tried oöphorectomy for cancer of any part other than the breast; but upon my advice, Mrs. Boyd performed the operation upon a woman, aged 35 , with extensive cancer of the cervix and vagina and a vesico-vaginal fistula. Her general condition was good. 
No atrophy of the growth occurred, but the vagina became much more lax, so that she could be examined more easily. She lived six months, and might well have done so without operation. She had some severe losses, and died after a very severe one.

Dr. Beatson has recently stated that in four cases of cancer of the uterus the only result obtained was diminution of sloughing and of bleeding. I believe that the operation has been tried for cancer of still other parts, with which one would suppose the ovaries to be less closely associated, but I do not know the results. In the BRITISH MEDICAL Journal of June 17 th Professor Hobday states from an experience of three cases that oöphorectomy seems to check the growth of a certain very obstinate papilloma of the vagina in bitches.

Another idea which suggests itself is that castration in the male should have similar effects. It may have, but the inference does not seem to me to be at all certain, for although developed from corresponding bits of embryonic tissue, nothing can be clearer than that the ovary and testis differ in most respects. The experiment, however, has been tried, and we must await the publication of the result.

By-and-by I hope to complete the notes of my cases. Although I cannot as yet, like Dr. Beatson, bring forward a case of apparent " cure," I do claim that in both my cases, Nos. I and 2, suffering has been alleviated and life prolonged. I should say that, but for the improvement which followed upon the oöphorectomy, No. 2 would now have been either in her grave or very near it. The cases I have narrated open up, as you have seen, numerous problems and a wide field for clinical work in connection with a disease so common that all have opportunities, and so distressing that all must long for some better means of dealing with it; and it is in the hope of drawing further attention to Dr. Beatson's suggestion, and of stimulating observation, that I publish these preliminary notes.

\section{REMARKS ON FRIEDREICH'S ATAXIA, WITH NOTES OF THREE CASES.* \\ By HERBERT BRAMWELL, M.D., M.R.C.S., Cheltenham}

THE following account of this rare disease is principally taken from the records of three typical examples of the affection, which I had the opportunity of watching for eight or nine years.

The disease gets the name Friedreich's disease or Friedreich's ataxia from having been first described by him in 1861 . He thought it was a form of locomotor ataxia, and subsequently suggested that the disease was due to defective development of the spinal cord. This opinion is strongly supported by Déjerine and Letulle, and recently the post mortem examination of the nervous system made by Dr. Byrom Bramwell on one of the cases I am about to describe, fully bears out this opinion. The disease has also been called the "hereditary form of locomotor ataxia" and "hereditary ataxia," but these names are objectionable, as the disease is not related to locomotor ataxia, nor is it truly an hereditary affection transmitted from parent to child, but rather a "family disease," occurring in several members of the same family, whose parents are quite healthy. Dr. Griffith, in the International Journal of the Medical Sciences for October, I888, proposed the name Friedreich's ataxia rather than Friedreich's disease, and this is the name subsequent authorities have adopted. Friedreich's ataxia bears most resemblance to locomotor ataxia, cerebro-spinal sclerosis, and ataxic paraplegia. But it is essentially different from all of them, as will be seen from the following description. The cases the history of which I am about to relate are members of the same family.

The eldest, Mr. B. B., was aged 24 at the time of his death, which took place last December from acute rheumatic fever and endocarditis. He was of decidedly blonde type of complexion, and very intelligent, occupying himself diligently in the study of music. He presented all the characteristic features of the disease. As an infant he was quite healthy.

\footnotetext{
* Read before the Gloucestershire Branch of the British Medical
Association.
}

When a small child he frequently used to have attacks of uncontrollable crying and laughing, which often produced a spasm of the larynx, cansing him to become quite black in the face, and on more than one occasion quite unconscious, seeming to his mother apparently dead. The attack would end by a gulping sound in the throat, after which he gradually regained his breath.

The first indications of his complaint were a "turning in of the right foot" and pains in the legs. These were noticed when he was aged $6 \frac{1}{2}$ years. He was at that time a robust, well-developed child, but extremely nervous, especially of carts or passing objects. He also suffered from occasional nocturnal incontinence of urine and fæces, and attacks of diarrhœa. The latter were brought on by any nervous excitement, and were considered by his then medical attendant to be due to his nervous temperament, and not to any gastrointestinal irritation. The pains which developed at the time appear to have been true lightning pains, but were never very severe, and were chiefly confined to the legs. At the age of $7 \frac{1}{2}$ years it was noticed his legs used to shake inordinately, and his gait was staggery. At this time also arching of the foot was first observed. At the age of 8 years he went to school, bis general health being good, but his gait was worse, and he was subject to uncontrollable fits of laughter. At I2 years of age he was head of a school of fifty boys, many of whom were 15 years old. At the age of 13 he was. placed under a medical rubber in London. His mother states that the rubbing, which was continued for several months, did him a great deal of harm, and it was, she thinks, the cause of peculiar nervous (hysterical or epileptic) attacks, which at this time he suffered from. These attacks usually came on in the morning before the patient was awake. He seemed as if he was mesmerised or hypnotised. During the attack he would go through his former school life, get out of bed, fight with imaginary boys, repeat his lessons, and recount his school experiences. During several attacks he thought he was a general, gave orders to his officers, imagined he was wounded in the back, and the bullet had lodged in the thigh, pointing out the exact spot.

Exactly the same story was repeated during several consecutive attacks, and he used to describe minutely his. favourite nurse, and order her to be sent for. He could not. remember her while aivake. These attacks would last from one to several hours, after which he would get into bed and fall asleep. On awaking he was quite well, and remembered nothing of what had happened. The attacks occurred every two or three weeks during the seven months while he was being rubbed, after which they ceased. At the age of 191 years he had a well-marked epileptic fit from no accountable cause. Since that time he has repeatedly been subject to epileptic attacks, and has had to be kept constantly under the influence of bromides. The family history, which of course applies to his younger brother and sister, is interesting in some respects, pointing to the etiology of the disease.

The father, who was very blonde, was delicate in early life, and got very stout between 20 and 30 years of age. $\mathrm{As}$ a young man he lived fast, but it is not definitely known that he ever had syphilis. The children do not manifest any signs of inherited syphilis. During his married life he was much given to rich living, and habitually consumed large quantities of wines and spirits, but without getting actually intoxicated. He suffered much from rheumatic gout, and died at the age of 40 from cancer of the stomach and liver. His relatives are rheumatic and gouty, but none of them manifest any nervous diseases.

The mother is alive and well, of nervo-sanguineous temperament, and very excitable but not hysterical. During the time she was bearing children her life was one of continual social excitement and high living, and she used to keep herself going by the continual use of stimulants. Her relatives are of a decidedly nervous type; one aunt suffered from epilepsy, a brother was drowned while rowing, it being supposed that he took a fit and fell into the water. One of her cousins is notably intemperate. There have been no cases of Friedreich's ataxia or locomotor ataxia on either side of the family. It is quite possible that the children were conceived when the parents were decidedly under the influence of alcohol.

There were six children. One died in infancy; and of the: 